\title{
Beauties at Work: Sexual Politics in a Chinese Professional Organization
}

Jieyu Liu, SOAS China Institute, Jieyu.liu@soas.ac.uk

This is an earlier version of the published article in NAN NÜ: Men, Women and

Gender in China, 18 (2). pp. 326-349. published by Brill. DOI:10.1163/1568526800182p05

\begin{abstract}
This article explores new forms of inequality experienced by young white-collar professional women in Post-Socialist China. Drawing upon ethnographic data collected during a six-month stay in a Chinese company in eastern China, I explore how sexuality is played out in its organizational culture. Through an analysis of management attitudes, everyday office encounters and organizational activities, I illustrate that the workplace culture can be eroticized. Masculine domination pervades company organization, with women controlled through the process of objectification, which intensifies vertical segregation by gender. Despite gendered and sexualized control in the white-collar workplace, I caution against misinterpreting Chinese women's responses by viewing them through the lens of inappropriate assumptions. I indicate how women's agency may be enacted, and reveal layers of response and resistance in the face of masculine domination at work.
\end{abstract}

Key words: sexuality, gender, organizational culture, white-collar profession, urban China

\section{Introduction}

During Mao's reign over China, the Cultural Revolution aimed to erase gender (and other) differences between citizens. These values were rejected in the early 1980 s, 
and the largely state-controlled media started to promote feminine figures and womanly values as appropriate role models. As economic development picked up in the 1990 s, the beauty economy boomed and has continued to grow ever since; for example, commercial companies employ models to advertise their products and many local governments have sponsored beauty contests to boost tourism. ${ }^{1}$ In the shadow of this growing consumerism and deployment of a sexualized femininity in the public domain, ${ }^{2}$ the sex industry has proliferated, catering to the demands of the increasing numbers of wealthy businessmen. ${ }^{3}$ This re-sexualisation of Chinese women means there is a need to examine the new sexual politics and forms of inequality that may have arisen in the Chinese workplace.

Existing studies on gender and work in China focused on sexuality, have examined the life of sex workers, the low-paid service workers. ${ }^{4}$ In contrast, this article examines the working experiences of highly educated young professional women, hailed by the Chinese media as 'white-collar beauties' (bailing liren). Despite the media's depiction of them living an enviable lifestyle in the front line of a pioneering modernity, these professional women are not immune from gender discrimination and sexual consumption. There is a gendered and sexualized story to be told. Building upon western feminist literature on gender, sexuality and organization, this article contributes to the development of global literature on gender, sexuality and work, but beyond the existing Euro-America model. Western scholars have already shown how organisational structures and workplace cultures are both gendered and sexualised, and that this is integral to organizational control and workplace relations. ${ }^{5}$ These studies, however, are grounded in a discourse of sexuality markedly different from that in China. Under Mao, gender was pursued through the desexualisation of women; opening up the economy has re-sexualised 
women but in a context in which the continuance of past restrictions on sexual expression and discussion provide them with little or no opportunity for sexual autonomy. This makes sexualised office encounters and business cultures that young professional women have to negotiate particularly problematic. ${ }^{6}$

Drawing upon ethnographic data I collected during a six-month stay in a Chinese company in eastern China, I explore how sexuality is played out in everyday interactions within the organizational culture of Chinese companies, and how the interplay of gender and sexuality contributes to the reproduction of masculine hierarchy and control in the workplace. Given the empirical basis of most scholarship on sexuality in organizations is Euro-American societies, the local sociality of gender and sexuality is often taken for granted. Using a Chinese company in China as a case study, this article aims to illuminate the importance of a local socio-cultural context in shaping the contour of sexualized control and resistance.

\section{Sexuality at Work}

Over the last three decades, western feminist scholars have criticized mainstream organization studies for overlooking the issue of sexuality. Like gender, sexuality is an integral part of work relations. At one end of the spectrum - sex as work - is the scholarship revealing how women are expected to perform aesthetic and sexual labour; sexuality is literally 'part of the job'. ${ }^{7}$ In the mainstream labour market there are still many roles designed to incorporate women's sexual appeal with a view to attracting male customers ${ }^{8}$ for example, service roles such as like flight attendants and waitresses. ${ }^{9}$ At the other end of the spectrum - sex in work - is the investigation into how sexual relations exist as a dialectic of control and resistance within 
organizations. For example, male bosses might exploit the relationship with their female secretaries; ${ }^{10}$ male workers may develop predatory sexual discourses and shop floor cultures that derogate and segregate women. ${ }^{11}$ In spite of this, or perhaps because of it, women actively engage in sexual politics. Rosemary Pringle found that female secretaries flirted with their male managers in order to gain concessions or even pursue for fun this kind of interaction. Peter Fleming's study of call centre workers exposed the organization's role in purposely controlling sexuality, and how an organization's apparent openness to sexuality masked how only certain sexual expressions deemed managerially useful were condoned. ${ }^{12}$

The sex-in-work scholarship informs the discussion of my data. To help analyse sexuality at work, I employ objectification theory in an analytical framework. According to the feminist theorists Nussbaum and Langton key features involved in the process of objectification include: 13

1. Instrumentality (treating a person as a tool for the objectifier's purposes);

2. Denial of autonomy (treating a person as lacking in autonomy and selfdetermination);

3. Inertness (treating a person as lacking in agency and also in activity);

4. Fungibility (treating a person as interchangeable with other objects);

5. Violability (treating a person as lacking in boundary-integrity);

6. Ownership (treating a person as something that is owned by another);

7. Denial of subjectivity (treating a person as someone whose experiences and feelings need not be taken into account);

8. Reduction to body (treating a person as identified with their body, or body parts); 
9. Reduction to appearance (treating a person primarily in terms of how they look);

10. Silencing (treating a person as if they are lacking the capacity to speak). Embracing these features, the objectification of women involves the act of disregarding the personal and intellectual abilities of a woman, and reducing her worth or role in society to that of an instrument for sexual pleasure that she can produce in the mind of another. ${ }^{14}$ This sexual objectification of women is widespread in western culture, permeating advertising, popular consumption, and of course pornography. China's market reforms, commercial culture and public discourse also embrace this sexual objectification of women, and this 'sexualization of the economy' has infected organizational culture. ${ }^{15}$ I utilize this sexual objectification framework to reveal the process by which female employees are sexualized, and how the sexualization assists in the maintenance of gendered and hetero-normative control and hierarchy in the organization.

While exposing the organizational mechanism reproducing gendered and sexualized control, I also warn against the practice of misinterpreting Chinese women's responses by viewing them through the lens of inappropriate assumptions. Although feminist scholars are generally more sensitive of inequalities and asymmetries on a global scale, there is a still long way to go toward understanding gender inequalities in East Asian societies: influential feminist scholarship remains grounded largely in an Euro-American axis that has defined its priorities. To date, major attempts to de-imperialize feminism have been framed in terms of an opposition between First World and Third World women, or more recently between the global North and the global South. ${ }^{16}$ While it is necessary to develop feminist analyses of the widening gap between rich and poor nations, the effect of such a 
focus has been to exclude Chinese women who are neither Western nor from the global South. By grounding analysis in local socio-cultural meanings and mechanisms of the Chinese gender-sex system, this article aims to shed fresh light upon the ways in which gender and sexuality are integral to the processes of compliance and resistance of masculine domination at work beyond Euro-American parameters.

Western studies on sex in organizations are grounded in a socio-cultural discourse of sexuality markedly different from that in China. Traditionally, it was acceptable for Chinese men to have multiple sexual partners (with concubines or prostitutes), while women were valued for their chastity. One mechanism to monitor the sexual purity of women was through the segregation of the sexes from the early years of life; the 'inner' space confined women to the household, out of public sight, was seen as necessary counterpart to the 'outer' space where men moved freely. ${ }^{17}$ Whether to cross this boundary or not was critical to distinguishing between women who were 'respectable' or 'pariahs'. The obsessive concern with women's respectability in pre-modern writings (which conveyed messages that women should avoid suspicion, shun male company, not gossip) implied that sexuality was central to women' social identity. ${ }^{18}$ By contrast, the social status of men was defined occupationally, dividing those who labor with their minds (the scholar elite) from those who labor with their hands (farmers and artisans). ${ }^{19}$

Twentieth-century reforms targeted the spatial concealment of women and moved them into the public space, outside the home, through mass mobilization into women's employment. ${ }^{20}$ The link between sexuality and women's social status, however, was never contested and in the official Maoist discourse, women were the principal targets and agents of sexual morality and respectability. Although Post- 
Socialist China has witnessed a boom of sexualization and commodification of women's bodies, women's sexual desire and autonomy remain moralized in the public space and continue to be key markers of 'reputable' women in the reform era. ${ }^{21}$ Indeed, boundary-crossing sex workers and (the few) women who write about their sexual experiences are publicly condemned as morally abhorrent and disreputable, while businessmen are free to enjoy the sexual consumption of women. ${ }^{22}$ This wider context and the deeply engrained link between sexuality and women's social status is the key to understanding the ways in which sexualized control and women's resistance take place in Chinese workplaces.

Women's respectability is closely tied to their sexual morality. 'Respectable' women's conformity to gendered sexual control, however, cannot be viewed simply as a sign of their powerlessness and so a more nuanced analysis is required to account for women's agency. Feminist scholars of non-western societies have highlighted the use of the 'gender mask' for women to gain social acceptance, ${ }^{23}$ and to demonstrate their capacities to produce 'public transcripts' appropriate to the needs of the moment. ${ }^{24}$ Thus, in a public space such as the office, women conform to a moral script in order to maintain their own (and their family's) respectability. There are also other social factors, such as the lack of state welfare provision, which mean that wider family and kinship networks remain the main source of funding and support for individuals in contemporary China, and thus for a woman to damage her reputation may have profound economic and social implications in a relational society. ${ }^{25}$ And so, while I agree with the call by western feminists to find new ways to communicate about sex and to reframe the boundaries of what is acceptable, ${ }^{26}$ caution should be raised against any simplistic demand grounded in a western feminist ideal for Chinese women to assert sexual autonomy for themselves publicly. 


\section{The Company}

This article is based upon data collected through an ethnographic study of a company situated in the Yangtze River Delta in eastern China. The Delta, which includes Shanghai, is one of the economic zones designated by the state for development of the market economy and has enjoyed rapid growth since the economic reforms of the 1980s. The company is one of the major state-owned foreign-trade companies in the region, specializing in exporting machinery; it has an annual export volume among the highest in eastern China. Because of its size, stature and profitability, it is a desirable employer for many local graduates. During the economic restructuring of the late 1990s many older staff took early retirement from the company, and as a result, the age of employees now range from 22 to 45 , with the majority in their late 20s and early 30s. In 2008, when I did my fieldwork, the company occupied two floors of a skyscraper and employed approximately 75 staff split into in four departments: sales (48), finance (6), human resources (6) and technical support (15). Through a local contact, I was introduced to the general manager of the company and allowed to work as an intern in the sales department for six months. During my stay, I conducted in-depth and repeated interviews with various members of staff in the company and took extensive observation notes. The company staff was aware of my identity as a researcher, and I was given considerable freedom to walk around, attend meetings and talk to employees. After I completed the fieldwork, I remained in contact with some interviewees in order to gain insights into developments in their life and the company.

The sales department, which was generally viewed as the core of the company, was sub-divided into six sectors depending on export region. There were three types of positions: sales assistant (most junior in the department), sales manager, and 
section manager (most senior in the department). When I first started my fieldwork, there were six male section managers, seven male sales managers and one female sales manager; twenty-four female sales assistants and ten newly recruited sales assistants (four men, six women, all of whom had graduated from top universities in the region). By 2015, the four men from the 2008 recruitment round had all became sales managers, including two section managers, but the six women were all still sales assistants.

Job segregation by gender had significant material consequences for women employees. ${ }^{27}$ The wage structure of the company consisted of a basic wage, welfare allowances and a bonus. The first two components were calculated according to a number of factors such as educational level, years of service and positional pay grade. The lowest level pay grade of a sales manager equalled the highest level pay grade of a sales assistant. However, the major differentiating factor in take-home-pay between grades was the bonus. The bonus of a sales manager was equal to 15 per cent of the profit contribution of all deals completed, and in a good month this could be more than a sales assistant earned in a year. Sales assistants, who may have made a significant contribution to the successful completion of a deal, received a bonus that was set within a fixed range with the exact figure determined by their line manager's assessment of their performance. This meant that while a sales manager's income was linked to the success of the company, the income of a sales assistant was subject to labour control.

In addition to the officially documented wage structure, there was an unspoken, opaque practice that was crucial to the economic polarization in the company: the annual distribution of dividends from company shares. Although the 
company was officially classified as state-owned, up to 30 per cent of its registered share capital was held by management and, unbeknown to sales assistants, sales managers were invited to buy company shares at a discounted price. Since the company was both highly profitable and had grown considerably in a relatively short period of time, several managers had become millionaires through the dividends they were paid. This polarizing income gap between sales managers and sales assistants was built upon a vertical segregation by gender but also paradoxically set out the material conditions in which gender and sexuality were played out in the company.

\section{The Official Stance}

When I first started working at the company the human resources assistant, Xiao Chen, gave me a booklet entitled Regulations On Employees' Everyday Behaviours. ${ }^{28}$ The booklet had eight pages in total dealing with everyday manners, office health and safety, and workplace discipline. The first page detailed the appearance requirements in the workplace. Men were not allowed beards; to wear short trousers, a vest or sleeveless shirt. Women were not allowed to wear sleeveless shirts, tummy revealing, low cut, or tight clothing, mini-skirts (skirts needed to be at least knee-length), or seethrough clothes.

The different clothing requirements for men and women were built upon an assumption that women's gender presentation is embedded in sexual ways. The prohibited clothing for women was associated with deviated women's sexuality while the men's dress code simply differentiated between casual and formal; i.e. men's sexuality was not used to define the parameters of their presentation in the workplace. As a consequence, management's different treatment of gender display sent an implicit message that women's sexuality should be monitored and controlled in the 
organization. In practice, I noticed that while women complied with the dress code all women wore feminine, but did not dress sexually, the style and colours of women's clothing were diverse. Moreover, none of the women wore a suit or formal dress; and during my entire stay I only saw one woman (sales assistant) dressed formally, and that was because she was about to fly to a trade fair that day. All men wore open collar shirts and jackets; on the days when clients were visiting, they wore suits to comply with the company's requirement.

Although the official regulations prescribed a desexualization of women's bodies to maintain the organizational image, my interviews with senior management revealed another story. When I asked how general manager Wang felt about managing female employees, he reflected, "women have significant functions. For example, in our industry, the pressure is high and there is lots of boring work. If all employees are men, I feel it very difficult for the organization”. Mr. Wang was married, in his mid-thirties and also the Party Secretary for the company. Perhaps because of his position, he was cautious in his words and tended to give ambiguous or indirect answers during my encounters with him. Here he revealed that women employees had significant functions but did not specify how. Instead he implied that the presence of women would reduce the pressure on men's work. However, most of his males colleagues were more explicit, and the phrase nannü dapei, ganhuo bulei (if men and women work together, the work won't be tiring) featured frequently in my interviews with them.

How would this pressure be reduced for men? During a conversation with a section manager, he gave me a clear answer to the question.

Q: What is the most suitable proportion of women in a workplace? 
A: I like a workplace with lots of women. It feels very pleasant.

Q: How?

A: I don't know how to say. It feels pleasant with women around, doesn't it?

Feeling like having one on the left and one on the right, it is extremely pleasant.

Q: How will this arrangement play in the workplace?

A: It can stimulate productivity. Life won't be boring. Through flirting with women colleagues, the atmosphere will be lifted up. I hope that in my section there are considerable levels of office banter as I find it can be inspiring.

The interviews with male managers indicated an encouragement of an eroticized workplace culture, which they considered conductive to boosting morale and productivity. This eroticization of the organization is formulated through, and symbolized in, the interactions between men and women at work. The underlying message is that women are brought into the workplace to stimulate male workers. The discrepancy between the management's desire to eroticize workplace culture and official regulation on appearance creates a paradox for women. While their desexualized body is an important symbol of the organization's professional image for outsiders, female employees were sexually objectified by the masculine management team within the organization; one consequence of this was that female employees were routinely subject to sexual innuendo at work.

The eroticized workplace culture also exhibited a new form of masculinity in Post Socialist China. ${ }^{29}$ This masculinity is a local presentation of "transnational business masculinity', which is characterized by 'its increasingly libertarian sexuality, with a growing tendency to commodify relations with women' and emerges as the dominant form on a global scale as a result of geopolitical struggles, multinational corporations, 
global markets and transnational media. ${ }^{30}$ In the context of East Asia, this hypermasculinity has been naturalized as "part and parcel of the economic development of many states and firms'. ${ }^{31}$ Zurndorfer points out the historical link between the past and present in the formation of Chinese masculinity; men's overbearing hegemonic behaviour in the reform era is closely linked to the traditional polygyny in pre-modern China, and their emasculinization in the pre-reform era. ${ }^{32}$

\section{Office Banter}

Xiao Zhang was slim, with a small good-looking face, and in her late 20s. She had a masters degree in human resources management, and was head of the human resources department. This made Xiao Zhang the only woman in the management team, and she often joked with me that the human resources department was a women's department, and the least important section in the company. Every three months, the company held a two-day management meeting. After I had been in the company for a couple of months, I attended one of these occasions. Xiao Zhang, her deputy, and I were the only women at the gathering.

In the opening report by General Manager Wang, he noted the company's initiative to build a factory on a recently purchased piece of land. During the course of his presentation, Wang mentioned that it would be good to plant trees around the factory, then turned to Xiao Zhang, smiled, and said 'the tree planted by us two will grow fast and strong'. All the other managers laughed. I glanced at Xiao Zhang and she remained silent without any facial expression. I then looked at General Manager Wang who seemed pleased with the reaction to his comment and uninterested in Zhang's reaction. Jokes like this occurred several times during the morning meeting. At lunchtime, all the participants of the meeting were invited to have a meal at a 
nearby restaurant. My table consisted of General Manager Wang, his deputy, a few section managers, and all three women. After asking Xiao Zhang how her wedding preparations were going, Mr Wang asked 'why did you choose him? I heard he looked like me'. Xiao Zhang replied without much facial expression, 'Yes, both you and him are round'. Then laughter burst out on the table.

Later, the deputy manager turned to me, and said that since I had the highest degree at the table, he would like to know my opinion in mate selection. He set out a scenario in which I should assess the men at our table as potential marital partners for myself, and asked whom I would select and why. I thought as an outsider to the company, I would be excluded from the banter and so his proposal took me by surprise. In response I explained mate selection in academic terms and diluted the sexual element. I could tell the deputy manager was disappointed with my answer as it did not achieve the 'atmosphere stimulating' effect he hoped for.

After this close experience of office banter, I met with Xiao Zhang separately, and asked her to reflect upon these interactions. Age and marital status seemed to play a key role in the women chosen by men as targets for their banter. Xiao Zhang felt she was the youngest among the three women present, not married, and so she the softest target. When I asked to elaborate, Xiao Zhang replied:

The first time I was really uncomfortable. They told dirty jokes about me, I wanted to find a crack on the ground and slip into it. In fact, at the time I wondered if he was joking or meant it. I felt really awkward and didn't know what to do. Nowadays I am completely used to it. I am neither angry nor do I mind. I have no reaction. When I hear the joke, I feel the same as when someone askes 'have you eaten?' 
Apart from the general manager, other male managers, including those of a rank similar to her also made jokes at Xiao Zhang's expense. ${ }^{33}$ She recalled:

Look, sometimes when we have lunch together, sales manager A will say something to me like 'beauty, you are my flower, you are my lover'. B, C, D (other male managers) also liked to joke at me. When I was planning my annual leave, a section manager heard and said, in front of my assistant Xiao Chen in the office, 'how come you planned to go to Sanya again? Haven't you already been there? We two went there together once'. Xiao Chen threw a glance at me immediately. I knew that she took it as true. I explained to her, 'he is joking, don't take it seriously'.

Xiao Zhang's experiences were common and permeated the interactions female sales assistants had with male managers. Section Manager Zhou was fond of telling jokes at his female assistant's expense but he also commented there should be a boundary, and that was physical contact; that is, men should not have a physical relationship with a female colleague:

A: Telling dirty jokes at women can satisfy a dry 'erotic' craving.

Q: What does a dry craving mean?

A: That you want to play with a woman but you cannot have a real sexual relationship with her. Married men already have responsibilities and don't need any further burden.

Occasionally the staff stepped over Section Manager Zhou's boundary. Before my time at the company there was a married sales manager who fell in love with one of his sales assistants and divorced his wife to marry his assistant. Both parties left the company soon after. In the case of singleton employees involved in a relationship, 
the company authorities took steps to separate the two people as they did not consider it professional for a husband and wife to work alongside each other. For example the woman would be moved out of the sales department into a supporting sectioneffectively a demotion because wages were lower outside the sales department. However, the man involved in the office marriage was more likely to be promoted, or even given greater responsibility as it was assumed he now had a family to provide for. In the six years after 2008, four couples followed this pattern.

Recent scholarship on sexuality in organization studies has concerned itself with whether office banter brings pleasure or harassment to an organizational setting. ${ }^{34}$ The Chinese office dynamics researched here indicate that the answer to this question is complicated. First, the office setting provided an arena for office banter to take place. Within the company, apart from separate offices for the general manager, deputy general manager and a few meeting rooms, all employees operated in an open plan space with individual desks compartmentalized by panels up to the head level when one sits down. Therefore, employees peering over these panels to chat to those nearby while remaining seated was common practice.

Two types of conversations took place between men and women on a day-today basis. The first type, work-related conversations, involved managers delegating tasks to the sales assistants. These conversations did not involve sexual connotations. Section managers and above tended to be more direct in their orders while sales managers (who were a rank higher than women assistants but relatively low within the organizational hierarchy) sometimes opened the conversation by complimenting the women; for example, by saying 'Xiao Zhang, since you are always so effective and fast, please help to get this done for me'. By assessing men's position in the 
organization, and their relation with them, women sometimes bargained with the sales managers when these requests were made: for example asking them to buy their lunch, or to bring them gifts from a forthcoming overseas business trip. From my observations of these interactions, I felt that women genuinely found such interactions pleasing.

The second type of conversation involved sexual banter in the office space. On most such occasions, the sexual banter happened all of a sudden: for example, the joker saw something in the news or heard something that prompted them to a sexual joke, which had nothing to do with the work in hand. Analysing at the contents of the men's sexual jokes, the discursive pattern usually involved an imaged affair between the joker and his target. It was often married senior managers (section managers and above, although occasionally some sales managers) who told sexual jokes. To an extent, these jokes provided a discursive landscape that embraced their paradoxical stance towards extramarital affairs: on the one hand, the managers disputed extramarital affairs as something to be avoided, but on the other hand, they were active in constructing imagined extra-marital relationships through the practice of joking. The jokes therefore provided an avenue for a sort of sexually cathartic expression enabling the men to play out a fantasy without disturbing the harmony of their family life. Through this discursive repetition, a sexual hierarchy was established and symbolized in contrast with the subordinate expressions of feminine desire and an aggressive drive of masculine desire. ${ }^{35}$

In general women told far fewer jokes than men because of their lower position in the organizational hierarchy. When they did tell jokes, they were mostly oriented towards sales managers (i.e. the rank closest to them) and concerned with the 
romance between the one being joked about, and his wife/girlfriend. None of the women told jokes that involved themselves as the person implicated in the relationship. The women, among themselves, sometimes gossiped about their male colleagues, covering topics such as personality (e.g. whether they were generous or mean), and dating histories (e.g. whether they philandered or not), but I was not privy to any conversations regarding male colleagues' bodies in contrast with the open comments made by men about their female peers.

When considering the impact of gendered sexual banter on organizational control, men's telling of sexual jokes at women was grounded in their sexual objectification of women, and continually reinforced through both formal and informal communication. Women were considered an instrument for men's pleasure and a tool to boost morale and productivity for the company (instrumentality). By imposing an imagined relationship between the woman being joked about and the joker, the joker claimed ownership of the woman and denial of her autonomy and subjectivity, often producing the silencing effect. Through the process of sexual objectification, women's position as a second-class citizen in the organization was symbolically reinforced.

Agency in public sexual discourse remains largely a male privilege. Men who initiated sexual jokes were clearly in favour of such a practice, claiming this to be an effective mechanism for stimulating the office atmosphere and bringing pleasure to all. Men who were good at telling sexual jokes were considered good icebreakers by senior management - a desirable quality in a client facing environment, which in turn enhanced their perception among senior male colleagues and so ultimately benefited their career development. By contrast, female employees were 
uncomfortable with the practice in their initial encounters but needed to learn to live with it due to its routinization in organizational culture (on average four to five times a day). For these women, something that men claimed was pleasurable frequently bordered on sexual harassment, with stressful consequences for young unmarried women. ${ }^{36}$ Unlike sex workers, who have already crossed the moral boundary and are so much freer to engage in sexual joking, ${ }^{37}$ the intersection of gender and professional class put these women's sexuality under a strict moral constraint. I did not encounter any woman in the company who freely and actively responded when sexually joked at in the public office setting; women's silence was the most common response. However, women's silence in public sexual discourse should not simply be interpreted as a sign of their powerlessness. Because of the way in which women's social status is judged by her sexuality, the damage to her sexual reputation is far more detrimental in a relational society. There were rumours in the organization about a woman from another foreign trade company that was good at 'everything' (including sexual joking) but because of this she was nicknamed 'public toilet' by the men, casting a dark cloud over her reputation. Through the repetition of rumours such as these, an implicit warning was sent out to advise people to distance themselves from this type of women. Taking into account the consequences of their behaviour in a society that put so much emphasis upon relational building and reputation, women considered it wise to appear silent and expressionless for the sake of maintaining their respectability.

There were also layers of responses contingent upon the context in which women faced men telling sexual jokes in public. ${ }^{38}$ In a confined masculine group setting such as the formal management meetings, women always remained silent when sexually joked at. In an everyday office setting, women strategized their 
responses by assessing the jokers' position in the organizational hierarchy. If the joker was a man from the senior management team (general manager and his deputy and section managers), women largely conformed to public scripts of masculine domination in sexuality; this was conditioned and facilitated by men's bureaucratic power. Yet after initial stressful encounters, women trivialized them and accepted the jokes as part of their day-to-day job. If the joker was a sales manager, women sometimes fought back by either invoking non-sexual jokes or emotional means to discredit the joker.

Mr Jing was 27 years old, single, and a sales manager. During my time at the company, I often observed him walk around the office telling sexual 'jokes' at women. On one occasion, a female sales assistant named Yin had just asked me my age when Mr Li passed by and overhead our conversation. He suddenly commented: 'I like eating both the big and small'. In pre-modern China, the 'big' implies the wife and the 'small' implies the concubine whilst eating is an indirect way to infer 'sleeping with'. By invoking this classical Chinese saying, Mr Jing tried to objectify both the sale assistant and me as his sexual compliance. Yin answered back sternly, go away, clean your mouth.

Afterwards, Yin warned me that I should be cautious around Mr Jing as he had a reputation for making sexual jokes in an attempt to gain the attention of women, and was notorious for being persistent. Other women assistants showed convulsion or chose deliberate avoidance if he came near. As there was no company policy or procedure for dealing with sexual harassment at the organization, warnings from other women about certain men had become a self-initiated protective mechanism to monitor men in the office. 
Not all men participated in telling sexual jokes. A couple of male sales managers confided in me that because they were shy, they did not know how to speak to women. They did not know how to tell jokes, let alone sexual jokes. As men in senior management set the tone by telling sexual jokes, the hegemonic corporate masculinity of the organization entails this aspect, which in turn creates a burden for men who did not fit with this model.

The routinization of men's telling sexual jokes at women reinforced and reproduced the heterosexual-normality model, which made it impossible for homosexuality to emerge at work. In Post-Socialist China, gay clubs, telephone support lines and other grassroots and activist organizations have started to emerge in some of the larger cities. Despite of its visibility, homosexuality is still closely associated with AIDS, crime, sickness and abnormality. ${ }^{39}$ All interviewees expressed surprise or shock at my question about homosexuality in the workplace, and generally talked about them as the 'other' in the society.

\section{Cheerleaders}

Office banter is a ritualised practice central to organizational culture which takes place at an interpersonal level in a public sphere. Here I examine collective organizational activities imbued with gendered and sexual meanings. One of the key features of state-owned companies, like the one where I did my research, is the tradition of regular collective events for employees. These events are considered part of an employees' welfare package and may be sports-related, team-building events or festival celebrations. When speaking of such events, General Manager Wang commented: 
Since the economic reform, Chinese society has entered a stage in which everything is measured economically. This is not necessarily a good thing. Through these events, perhaps the state hopes to strengthen citizens' faith and spiritual mood. These collective activities aim to boost the collective ideals and foster team spirit.

Mr. Wang felt that the collective activities of state-owned companies had an enduring relevance and were a necessary state control to infuse young people with collective ideals.

During my stay in the organization, there was a men's basketball event. The company needed to form a basketball team to compete with teams from other stateowned companies in the region and the collective spirit of each company would be expected to be on show throughout the event. For these events it was an unspoken rule that everyone invited must take part and if they chose not to participate they would be considered selfish and lacking in collective values. Given that the preparation, and the event itself, took place in the employees' spare time, i.e. breaks and weekends, this request was all the more demanding.

The senior management of the participating companies decided that, to enable women to participate in a "men's basketball event" each company also needed to organise a team of "basketball babes" (lanqiu baobei) to choreograph and perform a cheerleading routine. When this decision was confirmed, human resources manager Xiao Zhang was assigned the task of organising the company's team of basketball babes. She did so by carefully excluding employees with children and targeted young unmarried women and married women with no children. Recruitment for the team 
went well with limited resistance. The only significant exception was Miss Wang, who said:

Zhang asked me to be a basketball babe, explaining that it was a political task. If it is classified as a political task, one has to complete without any asking. But because every day we already work quite late, adding this political task, I felt it was too much to take on so I made an excuse of being not well to turn down her request. Later I told my mother and she scolded me badly, because she knew that if I turned it down, people at my workplace would have a bad impression of me.

Miss Wang's mother was right to be concerned, Xiao Zhang later confided in me that she felt Miss Wang did not want to be part of the team, and so she decided to exclude her from other activities, including work related opportunities.

Because the cheerleading team needed to rehearse at weekends, during all lunch breaks, and some evenings they sacrificed considerably more time preparing for the event than the men's basketball team (which practiced only at weekends). However, the main discontent in the team arose over how much of a woman's body should be revealed during the performance. Although male managers at the company had no direct link with the cheerleading team, some sought to influence the women's attire, saying that women should wear something to "excite one's eyeballs" (ciji yanqiu). Such a request was met with resistance from most women, and some even cited the workplace dress code which noted that low cut tops or mini-skirts were not allowed. During the negotiation over the women's clothing, the male management gave a distorted discourse of women and modernity: they claimed the women assistants were too conservative and traditional to wear revealing clothes. Ultimately a compromise was reached: the company's basketball babes wore a short sleeve T- 
shirt revealing the waist but not their cleavage and a mini-skirt but with tight shorts underneath.

During the weekend before the match, I received a call from the human resources manager Xiao Zhang in which she explained that one of the cheerleaders had fallen ill, the team required a replacement urgently, and would I step in. Had it not been for the fact that I was at the final stage of my fieldwork, I would have had little choice but to take part. After I declined, Xiao Zhang managed to talk another assistant into cheerleading at the last minute. On the day of match I sat in the audience with the employees of the participating companies. During the cheerleading performances I often heard laughter and explicit comments about the women's bodies from men in the audience: why bother to dance since the legs are so round?; "When talking about breasts, there are no proper breasts; when talking about buttocks, there are no proper buttocks"--implying these body parts are not sexy enough. Later, in the interviews with male managers, some commented that "although it was a men's basketball game, the basketball babes were the centre of attention". When the event was over, the women's embodied performance remained the topic of office banter for a while. Reflecting upon this event, both women and men expressed their doubt over the extent to which such an event boosted the collective ideals among employees.

This basketball event displayed a heterosexual model of workplace relations between male employees (athletes) and female employees (support actors), reinforcing a hegemonic masculinity and a sexualized femininity as well as institutionalizing heterosexual normality. Moreover, the event demonstrated key features involved in the objectification of women. Through the male gaze, women as a group became a tool to satisfy men's desire and pleasure (instrumentality). Denied 
subjectivity and autonomy, women's bodies were talked about, caricatured and consumed. The personal and intellectual capabilities of a woman were reduced to her body parts and through this objectification, a woman employee become a sex object, valourized and devalued, which in turn contributed to her second-class treatment in the workplace.

Feminist writers argue that sexual objectification is often linked to and caused by social inequality. ${ }^{40}$ Organization culture is not immune to wider socio-cultural discourse and in some respects the objectification of women in the Chinese company replicated the model of sexual economy in the Post-Socialist China. Zurndorfer's analysis of the cultural discourse of China's sexual economy, reveals how a sexualized landscape forms part of a wider public discourse which allows the bodies of young and intelligent women to be commodified and commercialized as economic resources. ${ }^{41}$ Similarly, in this company, gender inequality was institutionalized in the form of a vertical segregation between men and women; through a vicious circle the economic polarization by gender defined the hierarchical position between the exploiter and the one being exploited. Female employees were symbolically forced to 'sell' their bodies for the pleasure of collective consumption of men who possessed more economic resources. The public objectification of women is therefore closely linked to economic inequality between women and men within the organization and shaped by wider socio-cultural discourse in China.

\section{Conclusion}

This article explores the work experience of white collar professional women, mostly from the only child generation. In comparison with their mothers' generation of manufacturing workers, this generation enjoyed an occupational mobility through the 
educational investment they benefited from as the only child. However, the post-Mao economic reform has also witnessed the emergence of a sexual economy in which young women's bodies had become sexualized and commodified. ${ }^{42}$ This wider economic transition subjects these educated professional women to new forms of inequality at work.

Through an analysis of management attitudes, everyday office encounters and organizational activities, I have illustrated the way in which eroticized workplace culture has resulted in a form of domination and control of women through the process of sexual objectification. Sexual innuendo is implicitly encouraged by management to enhance productivity and morale. Facilitated by the vertical segregation between men and women, male-initiated sexual jokes were often intended to introduce expressions of subordinate feminine desire. When sexually joked about, women did not find this a pleasant experience as agency in public sexual discourse remains a male privilege. This sexual hierarchy in turn contributed to the reproduction of gendered segregation in the workplace.

While exposing the organizational mechanism in reproducing gendered and sexualized control, I warn against the practice of misinterpreting Chinese women's response by viewing them through the lens of inappropriate assumptions. A more nuanced analysis reveals women's agency and layers of resistance depending upon the context and men's position within the organizational hierarchy. Even when women remain silent and expressionless, their conformity to public scripts on sexuality should not be used as a measure of their powerlessness. Their response should be understood within the local sociality of gender-sex system in China which is grounded in a deeply engrained link between sexuality and women's social status. 
In a relational society that puts great emphasis upon reputation and networks, with profound economic and welfare implications, professional women conform to maintain their social 'respectability'.

Through the case study in China, this article reinstates that sexuality is deeply embedded in local social relations and speaks to the literature on sexuality in organization studies which hitherto has been mostly based in Euro-American societies. Would re-eroticization of workplace culture bring pleasure or harassment in an organizational setting? The Chinese office dynamics indicate that the answer to this question is complicated and the pleasure for women was dependent upon the contents, where and in particular, who possessed the agency in sexual encounters. Given that China is a place in which sexuality is closely tied to defining women's social identity and society is highly relational and emphasizes reputation, the emancipatory potential of re-eroticization of organizations could be premature for women. Instead, this article calls for the need to pay greater attention to the ways in which local sociality of gender and sexuality shapes the contour of control and resistance within the workplace rather than being trapped in a dichotomy of pleasure and coercion.

\footnotetext{
${ }^{1}$ Gary Xu and Susan Feiner, “Meinü Jingji/China’s Beauty Economy: Buying Looks, Shifting Value, Changing Place," Feminist Economics 13(2007): 307-23. Yang Jie, “Gender, Body Politics, and the Beauty Economy in China," Signs 36(2011): 333-57.

2 Harriet Zurndorfer, “Men, Women, Money, and Morality: The Development of China's Sexual Economy," Feminist Economics 22.2 (2016): 1-23.

${ }^{3}$ Elaine Jeffreys, China, Sex and Prostitution (London: Routledge, 2004).

${ }^{4}$ Here I follow the social constructionist's definition of sexuality and consider sexuality as socially organized through the institutions of society and sustained by a variety of discourses, scripts and everyday practices. The following books have examined how sexuality featured in work in Post-
} 
Socialist China but the occupations their studies focus upon are either sex industry or front line service industries. Zheng Tiantian, Red Lights: The Lives of Sex Workers in Postsocialist China (Minneapolis: University of Minnesota Press, 2009). Amy Hanser, Service Encounters: Class, Gender, and the Market for Social Distinction in Urban China (Stanford, CA: Stanford University Press, 2009). Eileen Otis, Markets and Bodies: Women, Service Work, and the Making of Inequality in China (Stanford, CA: Stanford University Press, 2012).

${ }^{5}$ For example, Lisa Adkins, Gendered Work: Sexuality, Family and the Labour Market (Buckingham: Open University Press, 1995); Peter Fleming, "Sexuality, Power and Resistance in the Workplace," Organization Studies 28(2007): 239-56.

${ }^{6}$ I have discussed elsewhere the sexualized business culture and its consequences for professional women; see Jieyu Liu "Sexualized Labour? White Collar Beauties in Provincial China," in East Asian Sexualities: Modernity, Gender and New Sexual Cultures edited by Stevi Jackson and Jieyu Liu with Juhyun Woo (London: Zed Books 2008), pp. 85-103. By contrast, this article focuses upon women's everyday encounters with their co-workers in the workplace.

${ }^{7}$ Christine L. Williams, “Sexual Harassment and Sadomasochism," Hypatia 17(2002): 99-117. ${ }^{8}$ See Adkins, Gendered Work, page 11-20.

${ }^{9}$ Pamela Abbott and Melissa Tyler "Chocs Away: Weight Watching in the Contemporary Airline Industry," Sociology 32(1998): 433-50. Christine L. Williams, "Sky Service: The Demands of Emotional Labour in the Airline Industry," Gender, Work, and Organization 10 (2003): 513-50. Karla Erickson, "Performing Service in American Restaurants," Space and Culture 7(2004): 76-89. ${ }^{10}$ Rosemary Pringle, Secretaries Talk: Sexuality, Power and Work (London: Verso, 1989).

${ }^{11}$ David L. Collinson, Managing the Shopfloor: Subjectivity, Masculinity and Workplace Culture (Berlin: Walter de Gruyter, 1992).

12 See Fleming, "Sexuality".

13 Martha C. Nussbaum, "Objectification”, Philosophy \& Public Affairs, 24(1995): 249-291. Please see page 257. Rae Langton, Sexual Solipsism: Philosophical Essays on Pornography and Objectification (Oxford: Oxford University Press, 2009), pp. 228-229.

${ }^{14}$ See Langton, Sexual Solipsism. Pp 160-162.

${ }^{15}$ See Zurndorfer, "Men, Women, Money and Morality”. P5. 
${ }^{16}$ See Chandra Talpade Mohanty “Under Western Eyes: Feminist Scholarship and Colonial Discourses," Feminist Review 30 (1988): 61-88. Gayatri Chakravorty Spivak, "Can the Subaltern Speak?,", in Colonial Discourse and Post-Colonial Theory: A Reader ed. by Patrick Williams \& Laura Chrisman (New York \& London: Harvester/Wheatsheaf, 1994), pp. 66-111.

17 Patricia Buckley Ebrey, Women and the Family in Chinese History (Hove: Psychology Press 2003). Pp. 25-26.

${ }^{18}$ Susan Mann, Gender and Sexuality in Modern Chinese History (Cambridge University Press 2011). Pp.71-72.

${ }^{19}$ See Mann, Gender and Sexuality in Modern Chinese History. P13.

${ }^{20}$ Liu Jieyu, Gender and Work in Urban China: Women Workers of the Unlucky Generation (London and New York: Routledge 2007).

${ }^{21}$ Harriet Evans, Women and Sexuality in China: Female sexuality and Gender since 1949 (London: Bloomsbury Academic 1997), p22. Evans discusses the significant gendered consequences of official discourse on sexuality. Despite the rhetoric of equality, women were still defined in 'scientific' terms as essentially different from and less sexual than men. In this monogamous picture, women were represented as the principal targets and agents of sexual morality and reason, so the double standard implicit in the Confucian principle of female chastity was recast in a gender-specific identification of female responsibility for the maintenance of social and sexual order. Geng Song and Derek Hird, Men and Masculinities in Contemporary China (Leiden: Brill 2013), p122. Through talking to white collar men, Song and Hird find while there are diverse masculinities in everyday practice, a biomedical model of innate gendered attributes pervades in the workplace, which impedes and limits women's career prospects.

22 Some ethnographic studies have found that double standards of sexuality between genders among the urban youth in China may not be as strong as in previous generations; see James Farrer, Opening Up: Youth Sex Culture and Market Reform in Shanghai (University of Chicago Press 2002); William Jankowiak, "Chinese Youth: Hot Romance and Cold Calculations," in Restless China, edited by Perry Link, Paul G. Pickowicz and Richard Madsen (Lanham, MD: Rowman and Littlefield, 2013), pp. 191212. In contrast, the narratives of my interviewees - the first adult cohort of the only child generation -revealed continued and significant double standards of sexuality and morality. One possible explanation is that this study was conducted in a provincial city where the youth were in some way 
behind their counterparts in more international cities such as Shanghai. Another possible explanation is the characteristics of researchers, i.e. the samples used by Farrer and Jankowiak may have been prone to include a segment of youth who were particular more open to western values. A national surveybased study revealed that China's youth may be more sexually active but double standards for what sexual behaviour in terms of gender is acceptable appear to be strengthening; see William Parish, Edward Laumann and Sanyu, A. Mojola "Sexual Behavior in China: Trends and Comparisons," Population and Development Review 33 (2007): 729 - 756.

${ }^{23}$ See Colette Harris Control and subversion: Gender relations in Tajikistan, (London: Pluto Press 2004). pp. 21-22.

${ }^{24}$ Colette Harris Muslim youth: Tensions and traditions in Tajikistan (Boulder, CO: Westview Press, 2006). Nitya Rao “Male 'Providers' and Female 'Housewives': A Gendered Co-performance in Rural North India,” Development and Change 43(2012): 1025-1048.

${ }^{25}$ Shang Xiaoyuan and Wu Xiaoming "The care regime in China," Journal of Comparative Social Welfare, 27(2011): 123-31.

${ }^{26}$ Andrea Cornwall and Susie Jolly, "Sexuality and the Development Industry," Development 52(2009): $5-12$.

${ }^{27}$ I have discussed elsewhere how a gendered discourse of technology and a spatial discourse around inside/outside contributed to the gender division of labour in this organization; however, the naturalization of gender disguised and legitimized inequality between men and women in the company. See Jieyu Liu, “White Collar Workers: Gender and Class Politics in An Urban Organization,” in Middle Class China: Identity and Behaviour edited by Chen Minglu and David Goodman (Cheltenham, UK and Northampton, MA, USA: Edward Elgar 2013), pp. 75-89. See also Ahu Tatli, Mustafa Bilgehan Ozturk and Hong Seng Woo, "Individualization and marketization of responsibility for gender inequality: the case of female managers in China," Human Resource Management 2016: 1-14. Tatli, Ozturk and Woo find similarly that the company management tends to attribute the unequal career path for men and women in their organization to commercial-only focus of the organization or obscure it under individual choices of women managers rather than to gender discrimination.

${ }^{28}$ All the names have been changed in order to protect the anonymity of the interviewees.

${ }^{29}$ In my study, I did not find the majority of the professional men I encountered fit with the 'metrosexual' image presented by white-collar men in Song and Hird's study. The difference between 
my finding and their conclusion may be attributed to the research design: mine was in an organizational setting where I could observe how men interacted with women while their study was primarily drawing upon interviews with men only. See Song and Hird, Men and Masculinities in Contemporary China 2013, p. 67.

${ }^{30}$ R. W. Connell, 'Men and Globalization', Men and Masculinities, 1(1998): 3-23. P.5

${ }^{31}$ L.H.M. Ling, 'Sex Machine: Global Hypermasculinity and the Images of Asian Women in Modernity', Positions: east asia critiques, 7(1999): 277-306. P.278

${ }^{32}$ Harriet Zurndorfer, "Polygamy and Masculinity in China: Past and Present." Changing Chinese Masculinities: From Imperial Pillars of State to Global Real Men. Ed. Kam Louie. (Hong Kong: Hong Kong University Press, 2016). 13-33.

${ }^{33}$ I did not witness men of a lower institutional rank make sexually referenced jokes toward Xiang Zhang.

${ }^{34}$ Gibson Burrell (1992) “The Organization of Pleasure," in Mats Alvesson and Hugh Willmott, eds., Critical Management (London: Sage, 1992), 66-89. Katie R. Sullivan, "With(out) pleasure:

Desexualization, gender and sexuality at work," Organization 21(2014): 346-364. Kari Lerum, “Sexuality, Power, and Camaraderie in Service Work," Gender and Society 18(2004): 756-76.

Christine L. Williams, Patti A. Giuffre, and Kirsten Dellinger, "Sexuality in the Workplace: Organizational Control, Sexual Harassment, and the Pursuit of Pleasure," Annual Review of Sociology 25(1999): 73-93. Silvia Gherardi (1995) Gender, symbolism, and Organizational Cultures (London: Sage, 1995)

${ }^{35}$ In a group setting, such as the company management meetings, another implicit function of men's sexual jokes was to use women as a prompt for men to interact with men. For example, General Manager Wang appeared enjoying and indifferent to Xiao Zhang's silence, which implied that the audience of his joke was really other men. This confirms Zurndorfer's observation that homosocial relations with other men remains a core part of Chinese masculinity in the past and the present. Harriet Zurndorfer, "Polygamy and Masculinity in China: Past and Present." Changing Chinese Masculinities: From Imperial Pillars of State to Global Real Men. Ed. Kam Louie. (Hong Kong: Hong Kong University Press, 2016). 13-33.

${ }^{36}$ The issue of sexual harassment at work has only recently been openly acknowledged as a problem, and has not yet been formally recognized in labour legislation. Thus there was no company policy or 
procedure for dealing with sexual harassment

37 See Ding Yu, "Negotiating Intimacies in an Eroticized Environment: Xiaojies and South China Entertainment Business," International Journal of Business Anthropology, 3(2012): 158-75; Zheng Tiantian, Red Lights.

38 There are similarities in gendered control between the Chinese companies I studied and the Japanese companies, for example, vertical segregation by gender and the paternalist culture. While suffering from structural discrimination, women in my study and the office ladies in Japan both demonstrated agency and resistance in their own office setting via emotional means. See Ogasawara Yuko, Office Ladies and Salaried Men: Power, Gender and Work in Japanese Companies (Berkeley: University of California Press 1998); Aviad E. Raz, Emotions at Work: Normative Control, Organizations and Culture in Japan and America (Cambridge, Massachusetts and London: Harvard University Press 2002). However, Ogasawara and Raz did not touch upon the sexual politics in Japanese companies. Further, there is a key difference in the background between professional women (university educated with strong personal aspirations) in my study and Japanese office ladies who were mostly graduates of two-year women's junior colleges and socialized to look on the office as a station on the road to marriage. These urban highly educated Chinese women's unprecedented ambition in personal development cultivated by a child-centred atmosphere in the intergenerational family became an important drive for them in their negotiations at work and in marital life; see more discussions on women's emotional resistance in my forthcoming book, Jieyu Liu, Gender, Sexuality and Power in Chinese Companies: Beauties at Work (London and New York: Palgrave 2016).

${ }^{39}$ See Evans, Women and Sexuality in China, p. 211.

${ }^{40}$ Catherine A. Mackinnon Feminism Unmodified Massachusetts: Harvard University Press, 1987), pp. 80-82. Nussbaum, “Objectification”.

${ }^{41}$ See Zurndorfer, “Men, Women, Money and Morality.” P.5

42 See Zurndorfer, “Men, Women, Money and Morality.”Pp.6-7. 